\title{
Using Gamification in an Online Community
}

\author{
Sanat Kumar Bista ${ }^{1}$, Surya Nepal ${ }^{2}$, Nathalie Colineau ${ }^{2}$, Cecile Paris ${ }^{2}$ \\ CSIRO ICT Centre \\ ${ }^{1}$ ANU Campus, North Rd $\quad{ }^{2}$ Cnr Pembroke and Vimiera Rds \\ Canberra, Australia Marsfield NSW, 2122 Australia \\ Firstname.Lastname@csiro.au
}

\begin{abstract}
Gamification has recently evolved as an approach to engage and encourage active participation of members in online communities. For an online community to start and proceed on to a sustainable operation, it is important that members are encouraged to contribute positively and frequently. This paper outlines the design and implementation of a gamification model for online communities and its instantiation for a specific online community we have developed in collaboration with a government agency to support welfare recipients transitioning to work. Besides enhancing community members' engagement, badges based gamification has offered us a way to monitor and analyse the online community, including categorising community members by the type of their contributions in the community. We present here some initial results from our online community.
\end{abstract}

Keywords-Badges; Gamification; Online Community; Social Networks; Social Media

\section{INTRODUCTION}

\section{A. Engagement and Gamification}

Not all members in an online community contribute equally to the community life. As pointed out by Jakob Nielsen [1], "In most online communities, 90\% of users are lurkers who never contribute, $9 \%$ of users contribute a little, and $1 \%$ of users account for almost all the action." If there are too few active contributors, an online community will struggle to become successful. It is thus essential to have a good number of active contributors for sustainability reasons. Enhancing engagement in a community could be one of the ways to motivate members to contribute, in turn improving the community's chances of sustainability. Higher engagement means a better social connection, which eventually encourages social cooperation among community members. However, increasing contributions in online communities is hard. Research in marketing and applications of marketing techniques in increasing corporate member base have suggested that inserting game dynamics to corporate websites could substantially enhance member participation $[2,3]$. The idea behind game dynamics is to make interactions more fun and appealing, as they would be in games. Recently (in 2010), this idea of inserting game dynamics into web interactions to enhance customer engagement has been referred to as gamification [4-6].

In line with this research, we believe that the application of gamification can enhance member contributions in online social communities. Although social communities have strikingly different objectives than commercial portals, engaging visitors still remains at the heart of their success.
The difference with commercial portals lies in the desired outcomes. For commercial ventures, the goal of enhancing engagement might be to generate extra revenue; for other online communities, it might just be to strengthen the social network. Therefore, we believe that a careful design is required to enable an online community to harness the benefits of gamification.

\section{B. Context}

Our work has involved designing, developing and deploying an online community in collaboration with a government agency to help them deliver differently their services to a target group of customers. The target group is in a transition phase, being asked (by legislation), to move from one type of welfare payment to another with the requirement to find a job. This new payment is typically inferior to that under the parental payment scheme. Understandably, this transition can be difficult and finding support from other community members in similar situation might be helpful.

The community has several aims. First, it is a place for the government to target its information and services when dealing with a specific group of welfare recipients. Second, it is a space in which we invite individuals to go on a reflection journey, in order to better prepare them for the transition and their return to work. Third, it is to bring people with similar concerns together, hoping that they will share experiences, ideas and tips, thus provide social, emotional and moral support to each other. All individuals in the community are strangers to each other - but they all share the same situation. The community is by invitation only, i.e., individuals receiving a specific type of welfare payments are invited to join the community, and as mentioned previously, these people do not know each other. Members can set up their profiles and decide how much they would like to disclose to others.

\section{Problem Statement}

The establishment of a new online community with a sustained level of member engagement is a challenging problem. There are three main challenges: (a) bootstrapping - how to bring the members to the community and keep them engaged during the initial phase of the community, (b) monitoring - how to monitor community activities under different categories like reading, rating, commenting, making buddies, etc., and (c) sustainability - how to sustain the engagement of the community not only during the initial phase, but also throughout the life of the community (or for a period of time). In our work, we decided to apply gamification strategies as one way to tackle these challenges. 
In the context of our community, it was important to ensure equality between members. This imposed some constraints in the type of incentives we could provide and in the way they could be deployed. For example, we could not categorise people into different membership groups nor could we offer financial incentives. To ensure that members express themselves freely, we needed to make sure that there was no element in the design that would give to members the perception of being judged. Furthermore, whereas we could encourage and promote people who engaged in the community, we could not single out others for not doing so. These requirements posed a particular challenge in applying gamification as many of its techniques are incentive focused. With these constraints in mind, our use of gamification has focused more on recognising members' contributions and on rewarding them with Badges for their achievements in the community. We have further used the data collected on badges as a way to monitor and visualise the community participation.

\section{Contributions and Organisation}

To address the above mentioned three challenges (i.e., bootstrapping, monitoring and sustainability) under our constraints, we have developed a specific gamification model. The main contributions of the paper can be summarised as follows:

- We propose a gamification model for online communities and define it formally.

- We present the design of our gamification model.

- We present a specific instance of our model in the context of our online community and report the initial results of its deployment.

The rest of the article is organised as follows. Section II provides a brief review of the related work. A gamification model for online communities is proposed in Section III, followed by its design process and implementation architecture in Section IV. We then present its implementation for our online community and initial results from its deployment in Section V. The final section draws the conclusion and presents possible future work.

\section{RELATED WORK}

Gamification has been popularly used by marketers and product managers to engage customers and influence desirable usage behaviour [7]. For example, DevHub (www.devhub.com) succeeded in increasing the number of users completing online tasks from $10 \%$ to $80 \%$ by adding gamification elements [7]. Engagement metrics like time spent on site was raised by $20 \%$ as compared to that before application of gamification techniques [6]. A New-York based food ordering website, Campusfood.com, experienced a $15 \%$ to $20 \%$ increase in the return of new users after adding points and badges features to their site [8]. In education, however, Lee and Hammer [9] have argued that gamification can be both positive and negative, and thus, it requires careful design. Using computers and psychology to persuade and shape user behaviour, and promoting the use of computers and games in instructional design are not new concepts [10-13]. However, building interactions based on those resources through gamification is an upcoming idea that has started penetrating the education and health sectors as well [14].

Other popular examples of raised user engagement driven by game techniques can be seen in various online applications such as eBay (ebay.com), Foursquare (foursquare.com), LinkedIn (linkedin.com), Livemocha (livemocha.com), MeYouHealth (meyouhealth.com), PracticallyGreen (practicallygreen.com), Khan Academy (khanacademy.org), to name a few [2, 15]. With its applications in several domains like marketing, politics, health and fitness, gamification is predicted to be a multibillion dollar industry by 2015 [8, 9]. In a recent article [15] in Time Business, Deterding discusses why gamification will rule the business world. Importantly, he underlines that gamification exploits basic instincts and uses technology to make things like competition easier.

There are several elements of gamification that have been in use. Loyalty, Points, Leader Boards, Badges, On Boarding, etc. have been mentioned as important elements of gamification capable of injecting game dynamics in non gaming environment [2, 4-6]. Although there are debates over the effectiveness of some elements in driving engagement (for example the debate over loyalty programs $[16,17])$, these elements are still popular.

For our implementation of gamification, we have chosen points and badges as our main design elements. The constraints of our context, in particular everyone was treated equally and with no judgement, prevents us from using elements such as leader boards and game based rewards.

\section{GAMIFICATION MODEL}

In this section, we formally present the gamification model that we have developed for our online community. It is formally represented as a seven tuple as follows:

$$
G_{m}=<M, A, C, P, B, R_{p}, R_{b}>
$$

Where $M$ is a set of members in the community; $A$ is the set of possible actions (or activities) that a member can perform within the community (e.g., login, rating, commenting, viewing, etc.); $C$ is a set of possible contexts in which a member can participate (e.g., discussion forums, live chat, etc.); $P$ is a set of points that can be assigned to members (e. g, 50, 100, 200, etc.); $B$ is a set of badges that can be assigned to members (e.g., reader, commenter, social etc.); $R_{p}$ is a set of rules for assigning points to members' actions (e.g., 50 points for each login, 20 points for commenting etc.); and $R_{b}$ is a set of rules for assigning badges to members (e.g., a scholar badge for achieving top 10 position for reading, rating and commenting activities).

An engagement of a member in the community is represented by three tuple $\langle M, A, C\rangle$. For example, if a member $m \in M$ takes a certain action $a \in A$ within a context $c \in C$, then the member's engagement is recorded as $(m, a, c)$. For example, Alice's reply in a forum is 
represented as (Alice, commenting, forum) and her invitation to Bob to become a buddy as (Alice, invite, buddy).

Each member's engagement in the community is awarded certain points. The number of points awarded to the engagement depends on both the type of action and context. In our model, a point $p \in P$ is assigned to a member's engagement using a rule $r_{p} \in R_{p}$ which can be represented as a mapping function:

$$
r_{p}: f(m, a, c) \rightarrow p
$$

Such rules are defined as part of the design of the gamification model for a particular community. The number of rules and the corresponding points associated with these rules are also derived from the application context. The exact values of the points and nature of the rules also depend on the application context.

A user can accumulate a number of points through different types of engagements. A number of members' engagements can be grouped together to represent a concept (e.g., reader, commenter, etc.). A member who has accumulated enough points will be awarded with a badge representing the concept. A badge $b \in B$ is assigned to the members using a badge rule $r_{b} \in R_{b}$ as follows:

$$
r_{b}: f\{(m, a, c, p)\} \rightarrow b
$$

This means that when members accumulate enough points due to their actions within different contexts, a badge will be assigned to them. The number and type of badges could be different in different communities. Furthermore, badges can be permanent (i.e., once a member earned the badge, s/he keeps it) or badges can be temporary (i.e., a member needs to maintain a certain behaviour to keep it).

\section{GAMIFICATION DESIGN AND IMPLEMENTATION}

\section{A. Design}

An important aspect of gamification is metrics, or scores as they form the basis of measurement. With a quantified representation of user participation and behaviour, measurements create a feeling of achievement among the members and help in motivating them to contribute more to the community. Thus, statistics lies at the core of gamification and plays an important role in influencing reward, status, achievement and competition [4]. Examples of statistics being related to status, achievement, competition and reward include eBay sellers' profiles (e.g., transaction history), number of views in YouTube, Facebook likes, Four Square check-in counts, etc. A popular computer programming question and answer site Stackoverflow ${ }^{1}$ uses various metrics based on activities like questioning and answering to collaboratively maintain the community. Contributors in the community are offered badges to reflect on the nature of their contributions, for example, badges related to whether they were good commenter or questioners.

We represent scores in terms of points that members acquire for their activities. These points are later converted into badges and we suggest these are displayed to the individuals so that members can reflect on their achievement. They could also be made public if appropriate. In our context, due to our constraint of having to treat all members equally, the badges secured are not made public to other members in the community.

Our design process consists of six phases as presented in Figure 1. In the first phase, we identify the set of contexts from the online community, where the gamification is to be introduced. This includes identifying the set of places within the community where a member can participate.

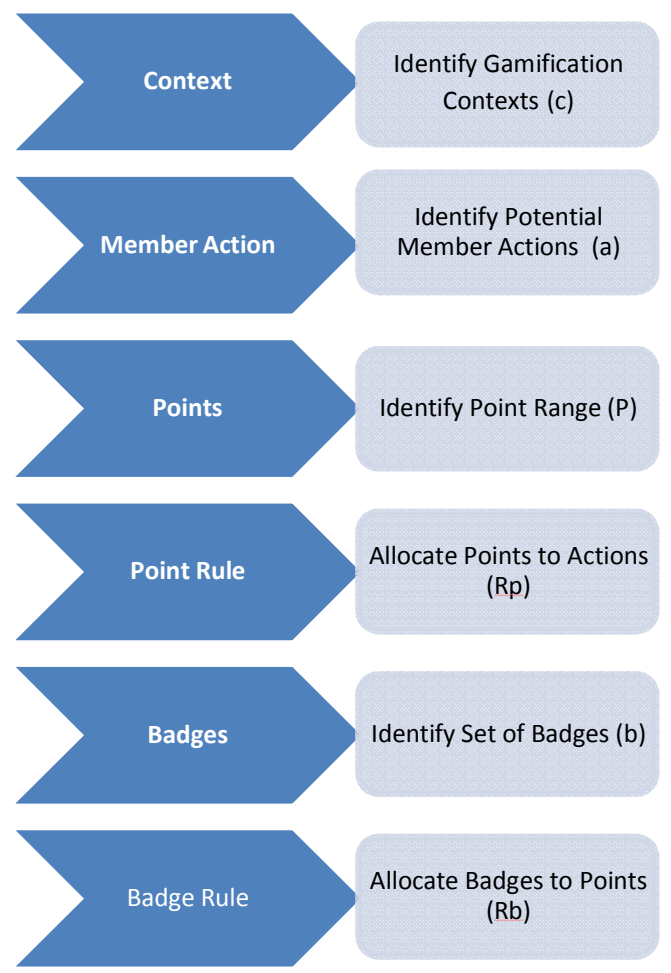

Figure 1. Gamification Design Phases (top to bottom)

Context identification is followed by identification of potential member actions in each context (second phase). As an example of this phase, Table I lists the gamification contexts and potential member actions identified for our specific online community.

In the third phase, a range of points to be allocated for different actions are identified and the rules to allocate these points to actions in different contexts are established in the fourth phase. The set of badges to be awarded are identified in the fifth phase, whereas the rules to allocate badges to points are performed in the final phase. This is illustrated in Table II, where all the badges we identified for our community as listed, together with the rules to allocate those badges. To explain the linkage of each of these phases to the formal model described in section III, we have made consistent use of the notations.

\footnotetext{
${ }^{1}$ http://stackoverflow.com
} 


\begin{tabular}{|c|c|}
\hline $\begin{array}{l}\text { Gamification } \\
\text { Context (c) } \\
\end{array}$ & Action (a) \\
\hline Registration & $\begin{array}{l}\text { Complete Registration } \\
\text { Early Bird registration }\end{array}$ \\
\hline Visit & Unique Sign-In \\
\hline Forum & $\begin{array}{l}\text { Commenting } \\
\text { Reading } \\
\text { Rating }\end{array}$ \\
\hline Buddy & $\begin{array}{l}\text { Send Invitation } \\
\text { Accept Invitation }\end{array}$ \\
\hline Activity & $\begin{array}{l}\text { Complete Standalone Activities } \\
\text { Complete Collaborative Activities }\end{array}$ \\
\hline Toolkit & $\begin{array}{l}\text { Visit Resources } \\
\text { Rate Resources } \\
\text { Feedback on Resources } \\
\text { Comment on Resources } \\
\text { Comment Ratings }\end{array}$ \\
\hline Live Chat & $\begin{array}{l}\text { Participating in Live Chat } \\
\text { Suggesting Topics for Live chat }\end{array}$ \\
\hline Myth Buster & $\begin{array}{l}\text { Visit Myth Buster Page } \\
\text { Myth Buster Rating, Feedback and Commenting }\end{array}$ \\
\hline
\end{tabular}

Points are awarded to the member who takes certain actions within a context. The point rule defines how many points to allocate for a particular action. Badges are awarded on the basis of point scores.

There are two types of badges: permanent and temporary. Each of the temporary badges is refreshed fortnightly. To regain such badges, members have to sustain a particular behaviour of being ranked among the top ten performers. Permanent badges are retained by members throughout their time in the community. Table II shows badges types for our community.

Choices of the badges must take into consideration the different activities that community members can perform under the identified contexts. In our community, for example, the five important activities members can perform include: Reading, Rating, Commenting, Making Buddies and Working on weekly tasks. To encourage members' participation in each of these activities, we designed and allocated badges accordingly. Figure 2 highlights the important member activities and their badges for our community. Rules to obtain each of these badges are explained in Table II.

The badges with suffix Plus were introduced as reinforcement badges to emphasise member contributions in that area. To prevent saturation, only some of the badges were conferred as permanent. Others lapse after an interval of time and need to be regained. In addition to these badges, two other badges, namely Next Step and Early Bird were offered to reward successful and early registrations. Both VIP and VIP Plus badges were offered to encourage members to return to the community often.

\begin{tabular}{|c|c|c|}
\hline Badge (b) & Awarded To $\left(R_{b}\right)$ & Type \\
\hline Next: & All Registered & Permanent \\
\hline Ear & $\begin{array}{l}\text { All Registered within two } \\
\text { weeks of Community } \\
\text { launch }\end{array}$ & Permanent \\
\hline VIP & $\begin{array}{l}\text { Fortnightly top ten scorers } \\
\text { for unique Sign-ins (two } \\
\text { consecutive sign-ins } \\
\text { are considered unique } \\
\text { if they were separated } \\
\text { by at least two hours of } \\
\text { time difference) }\end{array}$ & Temporary \\
\hline VIP Plus & $\begin{array}{l}\text { Members qualifying for } \\
\text { the VIP badge twice in a } \\
\text { row }\end{array}$ & Temporary \\
\hline & $\begin{array}{l}\text { Members sending out and } \\
\text { accepting at least two } \\
\text { buddy invitations }\end{array}$ & Permanent \\
\hline Social Plus & $\begin{array}{l}\text { Members sending out and } \\
\text { accepting at least five } \\
\text { buddy invitations }\end{array}$ & Permanent \\
\hline & $\begin{array}{l}\text { Fortnightly top ten scores } \\
\text { for reading and rating } \\
\text { posts, resources and } \\
\text { comments }\end{array}$ & Temporary \\
\hline Reader Plus & $\begin{array}{l}\text { Members qualifying for } \\
\text { the Reader badge twice in } \\
\text { a row }\end{array}$ & Temporary \\
\hline Commenter & $\begin{array}{l}\text { Fortnightly top } 10 \text { scorers } \\
\text { for posting comments }\end{array}$ & Temporary \\
\hline Commenter Plus & $\begin{array}{l}\text { Members qualifying for } \\
\text { the Commenter badge } \\
\text { twice in a row }\end{array}$ & Temporary \\
\hline Enthusiast & $\begin{array}{l}\text { Top } 10 \text { scorers in Weekly } \\
\text { Community Activities }\end{array}$ & Permanent \\
\hline Schola & $\begin{array}{l}\text { Fortnightly top } 10 \text { scorers } \\
\text { for balanced reading, } \\
\text { rating and commenting } \\
\text { activity }\end{array}$ & Temporary \\
\hline Enlightened & $\begin{array}{lr}\text { Members } & \text { whose } \\
\text { contributions receive } \\
\text { more positive ratings and } \\
\text { less negative ratings } \\
\text { (refreshed fortnightly) }\end{array}$ & Temporary \\
\hline
\end{tabular}




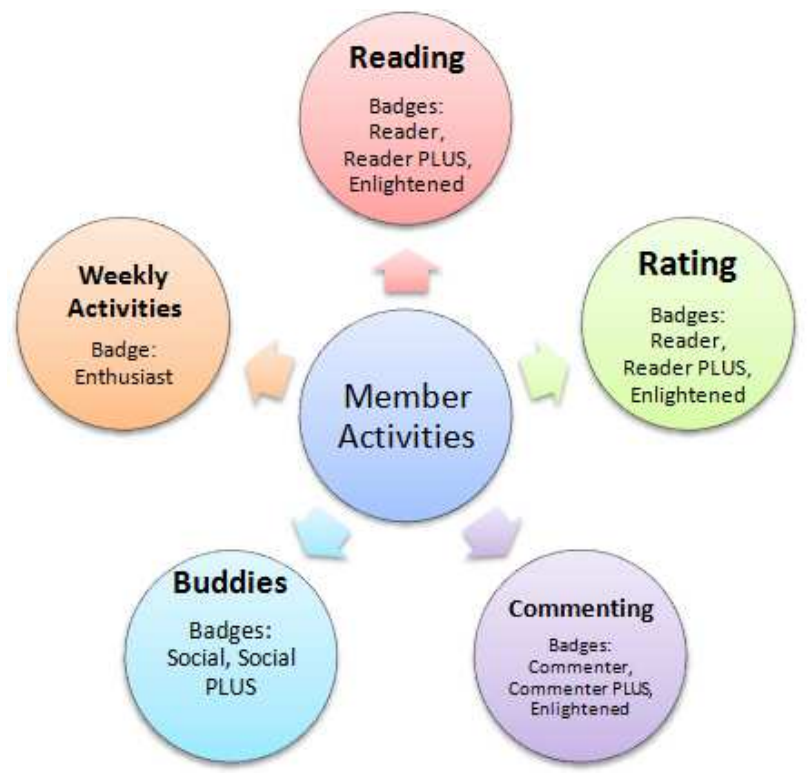

Figure 2. Member Activities and Badge allocation

The gamification data model consists of three major entities, the User, Activity and Badges. Figure 3 presents a high level data model with these three entities. Community members (users) perform activities, in several possible contexts, for which they are awarded points. On the basis of the points scored, users secure one of the different possible Badges.

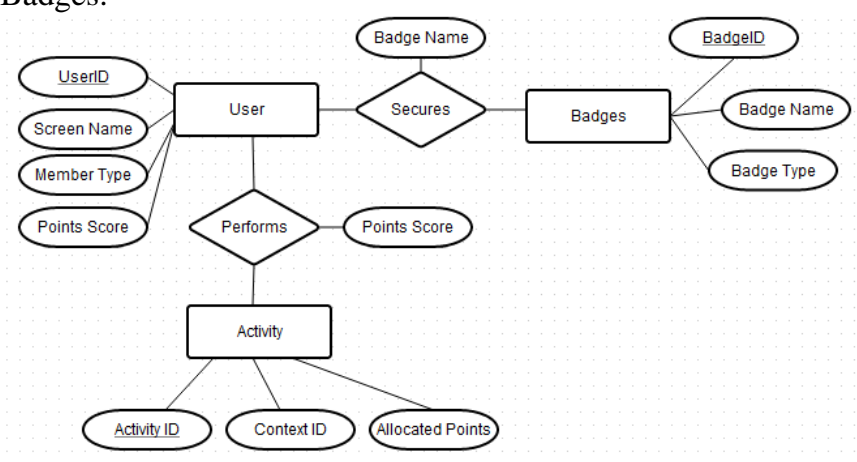

Figure 3. High Level Data Model for Gamification

\section{B. Implementation}

The gamification architecture (Figure 4) comprises of three main data sources, the interaction data, the user data and the gamification data. Interaction data holds the complete user interaction details of the whole community. This data together with the user data is also utilised by other community platform features. There are typically two kinds of users in a community, the general members and the moderators. Like general members, moderators also post messages and replies in different forum contexts. However, they are not entitled to points and badges. This distinction in roles, together with other necessary user information is supplied to the gamification data and sourced by the user data.

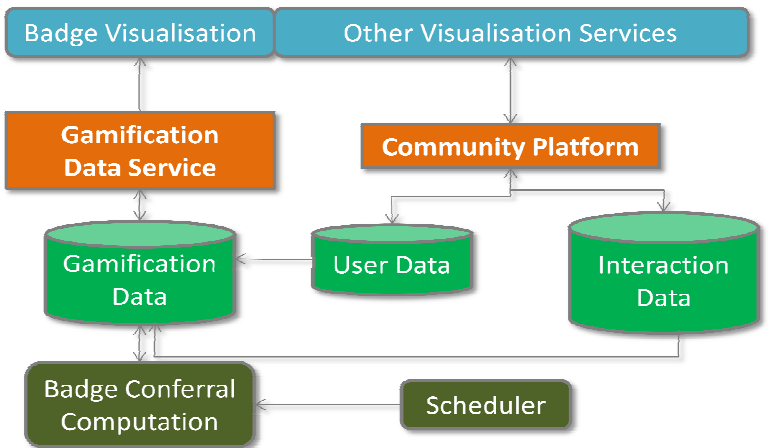

Figure 4. Gamification Implementation Architecture

The scheduler runs badge conferral computation once in every 24 hour. This triggers the computation of points and updates the badge data for each member. Depending on the situation, members can gain a new badge or lose a temporary badge if they do not qualify for it again. The gamification data service layer acts as an intermediary layer between the gamification data and the badge visualisation which is the front end visible to the end users.

\section{GAMIFICATION IN OUR COMMUNITY, OBSERVATION AND ANALYSIS}

The model was implemented in our specific community. (See Tables I and II above for the specification of the contexts and actions in our community, as well as the badges available. As the community is currently deployed and running, we cannot disclose the points awarded for each action in this paper.) Figure 5 presents the screen shot of the landing page of the community where badge achievements of the member are listed. In addition to the graphical display, members also get notifications in the designated area. Figure 6 presents a snapshot of the personal statistics points for a dummy user. Details of point scores are available under the personal statistics section of the community portal. This page lists points scored in each context and also explains to members how they can be obtained.

In this section, we focus on the monitoring aspects of the problem. We present some of our initial observations and analyse the community trend on the basis of badge conferrals. Our objective here is to show how a gamification element could help in monitoring, i.e., interpreting and analysing the interactions in a community. 


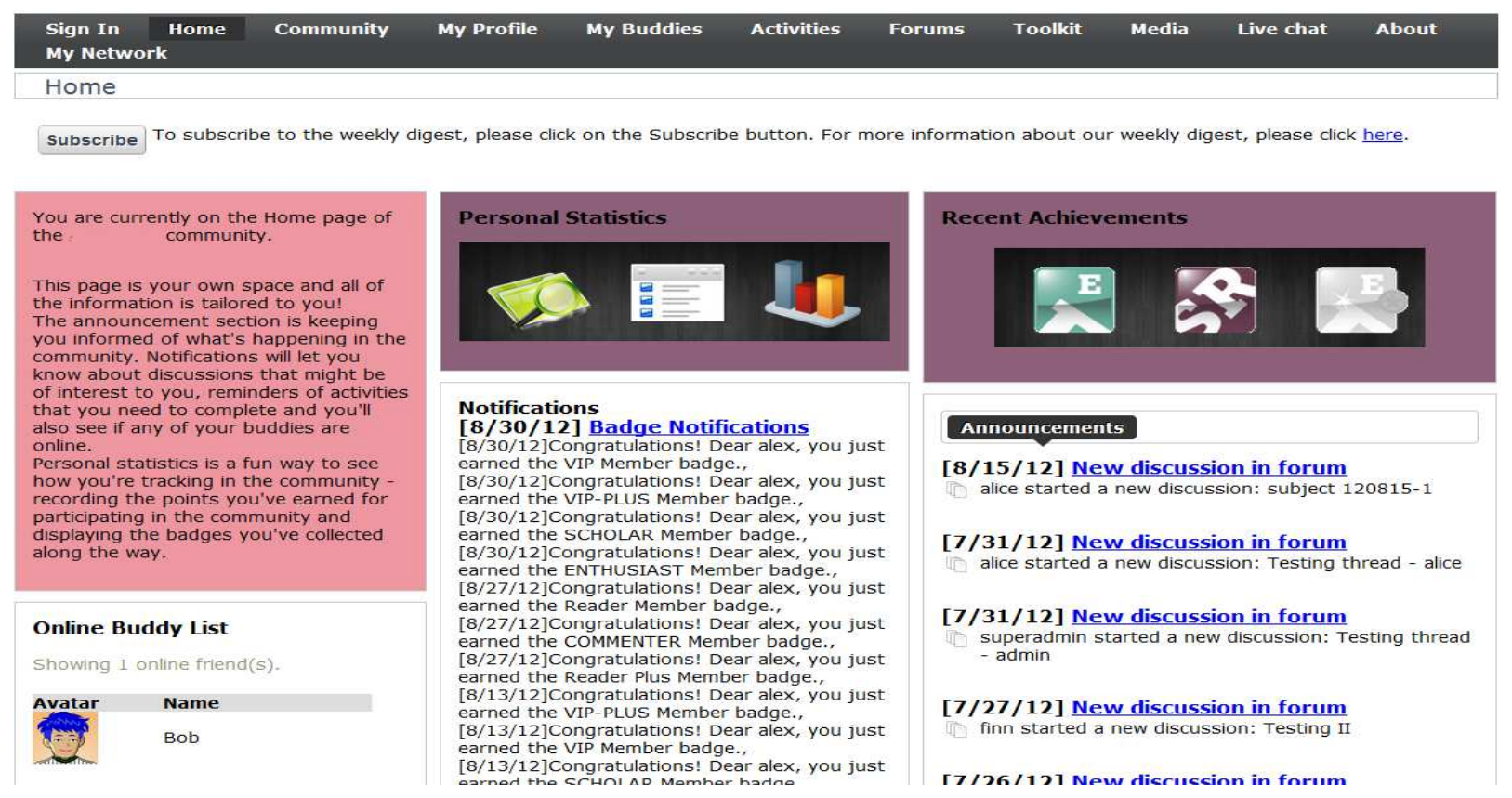

Figure 5. Snap Shot of the Community Landing Page

Personal Statistics
Registration Points: 1000
You earned your Registration Points by registering
to the Next Step community.

Figure 6. Snap Shot of a Dummy Member's Point Scores

The online community started in March 2012 and will stay open for at least 12 months. Invitations were sent out to about 3,000 prospective members, first in March 2012, and then again, in June 2012. Another round of invitations is planned for September 2012.

We start our description with some expert observations of the community and proceed on to describe the badge statistics. The community at the moment is small sized (being an invitation only community), and, in average, $5 \%$ of the members, out of the total registered, visit the community on a daily basis. After a few weeks of the community launch, we noted that a group of members regularly visited the community and it was the same group that participated in community activities like commenting and reading. A unique feature of this community is the set of tasks that members can do in a weekly basis. These tasks are targeted to individuals as well as groups. Members focus on some simple skill building assignments such as writing a good CV or identifying gaps they have in their skills. Members participated mainly in individual activities (collaborative activities require working in small groups with one's buddies $^{2}$ ). There were only a few interactions in the buddy activity of the community. As a result, no Social (or Social Plus) badges were awarded.

We now present some badge data from the community and analyse the results to explain the community behaviour. We collected 16 weeks (4 months) of badge data from Week 6 to Week 21 of the community launch. We discarded the early weeks as it took some time for members to register (due to limitations in the method used to send invitations) and start participating in the community activities.

We first observe what community features were mostly exploited by the members, as evidenced in the badge data. As mentioned earlier, only a few members used the buddy facility in the community, and thus none was given the Social badge. We thus discard this badge in our analysis. Figure 7 presents the percentage of the community members holding the other badges.

\footnotetext{
${ }^{2}$ With the buddy feature, community members were able to invite other members to be their buddy and share information or work together on activities.
} 


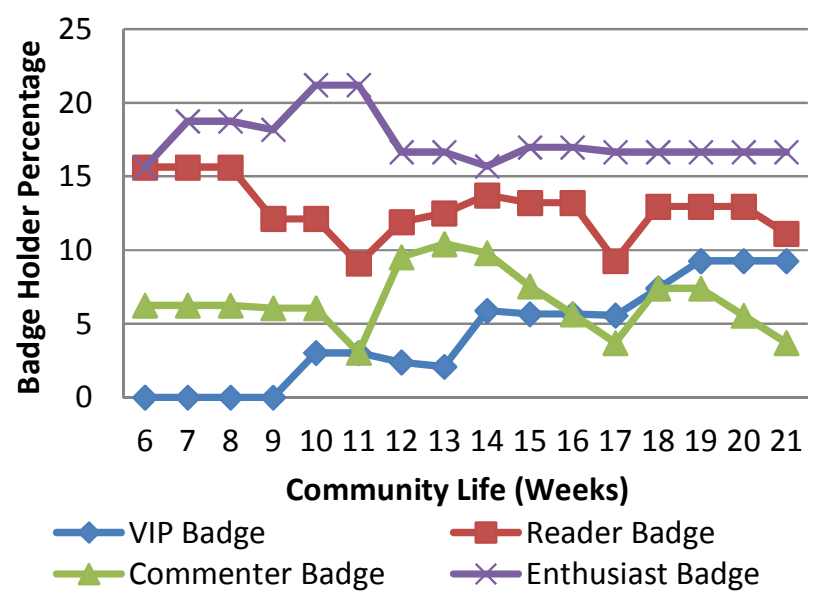

Figure 7. Comparison of Badges Earned During the First Four Months

It is important to note that the new members joined the community during Week 12 (as a result of the second round of recruitment).

We can see that the weekly activities were one of the attractive features among community members at the beginning of the community. This is shown by the percentage of members holding the Enthusiast badge in the community. However, the trend shows that the percentage holding this badge did not increase along the community life. Reading and rating community contents such as forum posts and toolkit resources remained popular as suggested by the reader badge figures. The low percentage of members holding the commenter badge suggests that more members were reading and rating in the community than actually posting or replying to the posts. Members' percentage holding the VIP badge (which indicates number of unique sign-ins) shows little increase until the community reached Week 12, when the new recruitment resulted in new members. Two consecutive sign-ins are considered unique if they were separated by at least two hours of time difference.

Further interesting analysis is done by observing reinforcement badges. VIP, VIP Plus, Social, Social Plus, Reader, Reader Plus, and Commenter, Commenter Plus represent the reinforcement variety of badges. The existence of plus badge here is dependent on the reinforcement nonplus version. We first analyse the reinforcement VIP, VIP Plus results shown in Figure 8.

The VIP reinforcement badge analysis gives an insight into the population of frequent visitors. From Figure 8 , we can see that at the beginning and until week 10 , there were very few unique sign-ins. After Week 13, unique sign-ins increased in a progressive manner, as indicated by the badge conferral data. VIP plus was offered to members qualifying for VIP badge twice in a row. Increase in population of this badge indicates that there is a positive growth in a group of members coming back regularly.

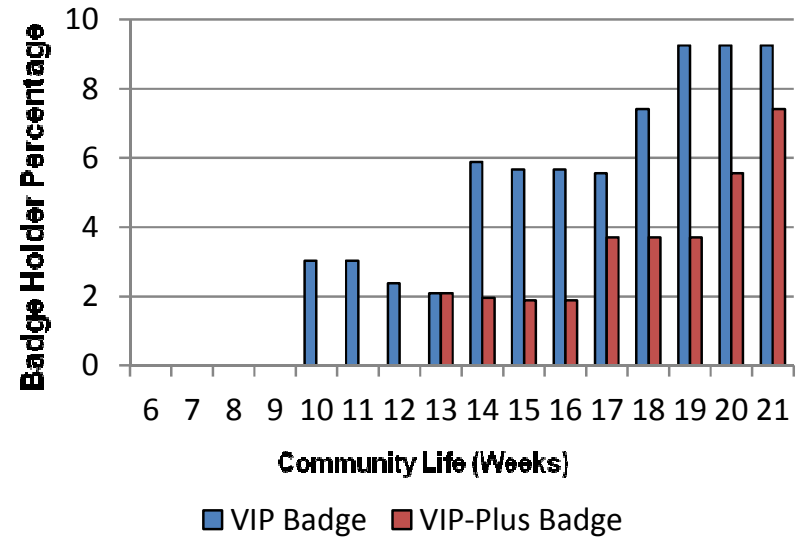

Figure 8. Comparison of Reinforcement VIP- VIP Plus

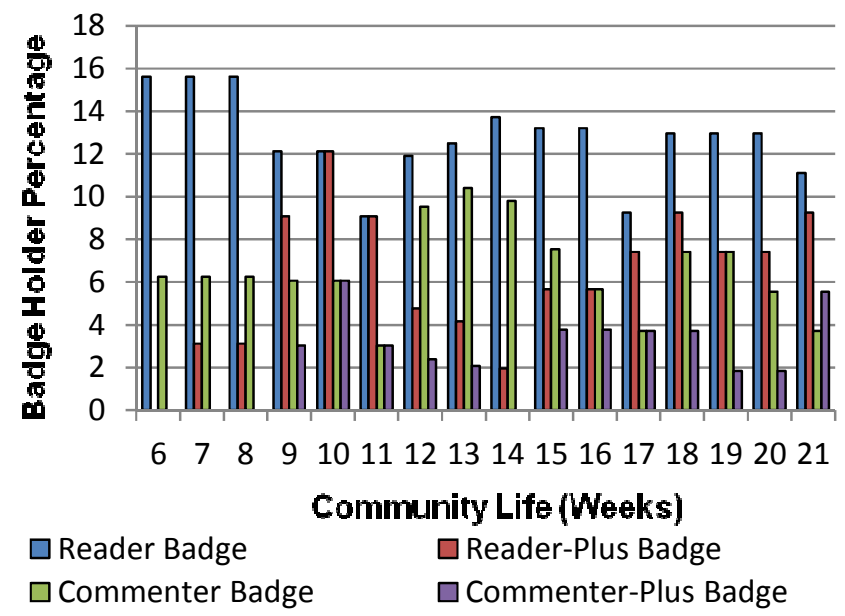

Figure 9. Comparative Populations of the Remaining Reinforcement Badges

The badge data here gives an idea of how different activities were picked up and whether they were carried out by new members or a set of recurrent members.

As shown by the data in week 6 from Figure 9, the community picked up reading and rating activities at this point. This was soon followed by commenting and posting activities. Starting Week 7, Reader plus badges were conferred, indicating that reading and rating activities were now being carried out by recurrent members. Recurrent posting and commenting started only at Week 9; this is shown by the commenter plus badges appearing at that point. After week 9, we can see ups and downs in the awarding of badges during the community life. Starting week 12, we see increment in commenter badge, indicating the involvement of the new group of members in commenting activities.

From the results presented above, we see that gamification data can be useful in monitoring community behaviour, as it provides an abstraction of the data. Both active (like commenting and posting) and passive (like signing in, reading) behaviours of members can be analysed using gamification data. Further, observing plus badges in 
the community tells us what percentage of the community sustains a specific behaviour. This is an important parameter to analyse sustainability of an online community.

\section{CONCLUSION, LIMITATIONS AND FUTURE WORK}

In this paper, we have presented the design and implementation of a gamification model for online communities, with its instantiation in an online community designed for a government agency with the aim of providing support services to welfare recipients transitioning back to work. Our aim with the proposed gamification model is to improve three aspects of the community: bootstrapping, monitoring and sustainability. We have described our Point and Badges based gamification design, and presented an initial analysis of the badge conferral data in our community. Our focus in this paper was on the monitoring aspect. We believe that badge data analysis helps community observers or moderators to visualise and monitor the community at a glance.

It would also be interesting to study the effectiveness of our proposed gamification techniques in encouraging and motivating member participation (bootstrapping and sustainability). The community trial is still going on, and it is too early to conduct a sustainability study. Due to the inherent design constraints (such as equality and no penalty), there were limitations on the gamification elements we could employ, preventing us from using a range of gamification elements for the purpose of bootstrapping. In the future, we plan to do further analysis of the data with respect to the effectiveness of gamification on bootstrapping and sustainability of the online community.

\section{ACKNOWLEDGMENTS}

This research has been funded under the Human Services Delivery Research Alliance (HSDRA) between the CSIRO and the Australian Government Department of Human Services. We would like to thank Payam Aghaei Pour, Hon Hwang, Brian Jin, Alex Sun and Bo Yan for their contribution to the implementation of this work.

\section{REFERENCES}

[1] Nielsen, J. Participation Inequality: Encouraging More Users to Contribute. Jakob Nielsen's Alertbox 2006 [cited 28 August 2012]; Available from: http://www.useit.com/alertbox/participation_inequality .html.

[2] Radoff, J., Energize your Business with social Media Games2011, Indianapolis, USA: Wile Publishing Inc.

[3] Reeves, B. and J.L. Read, Total Engagement2009, USA: Harvard Business Press.

[4] Bunchball. Gamification 101: an introduction to the use of Game Dynamics to influence Behaviour. 2010 [cited 15th November 2011 ]; Available from: http://www.bunchball.com/gamification101.
[5] Deterding, S., et al. Gamification:Using Game-Design Elements in non-gaming Contexts. in PART 2 Proceedings of the 2011 Annual Conference on Human Factors in Computing Systems. 2011. Vancouver, BC, Canada: ACM.

[6] Zichermann, G. and C. Cunningham, Gamification by Design: Implementing Game Mechanics in Web and Mobile Apps2011: OReilly.

[7] Arias, T., The Gamification Handbook - Everything You Need to Know about Gamification2011: Emereo Pty Limited.

[8] MacMilan, D. 'Gamification': A Growing Business to Invigorate Stale Websites. 2011 [Cited 27th November 2011]; Available from: http://www.businessweek.com/magazine/content/11_0 5/b4213035403146.htm.

[9] Lee, J.J. and J. Hammer, Gamification in Education: What, How, Why Bother? Academic Exchange Quartely, 2011. 15(2): p. 146-150.

[10] Fogg, B.J., Persuasive technology: using computers to change what we think and do2003: Morgan Kaufmann Publishers.

[11] Ling, K., et al., Using Social Psychology to Motivate Contributions to Online Communities. Journal of Computer-Mediated Communication, 2005. 10(4): p. 00-00.

[12] Malone, T.W., What makes things fun to learn? heuristics for designing instructional computer games, in Proceedings of the 3rd ACM SIGSMALL symposium and the first SIGPC symposium on Small systems1980, ACM: Palo Alto, California, USA. p. 162-169.

[13] Niebuhr, S. and D. Kerkow, Captivating Patterns - A First Validation Persuasive Technology, Y. de Kort, et al., Editors. 2007, Springer Berlin / Heidelberg. p. 4854.

[14] Lauby, S. Gamification Coming to a Workplace Near You. Powering Small Business Success 2012 [cited 28 AUG 2012]; Available from: http://www.openforum.com/articles/gamificationcoming-to-a-workplace-near-you.

[15] Deterding, S., Gamification: designing for motivation. interactions, 2012. 19(4): p. 14-17.

[16] Dowlin, G.R. and M. Uncles, Do Customer Loyalty Programs Really Work? Sloan Management Review, 1997. 38(4): p. 71-82.

[17] Uncles, M.D., G.R. Dowling, and K. Hammond, Customer loyalty and customer loyalty programs. Emerald Journal of Consumer Marketing, 2003. 20(4): p. 294-316. 